Original Contribution

\title{
REPRODUCTION OF MUSCULAR DYSTROPHY IN BROILER CHICKENS THROUGH EARLY NUTRITION WITH DEFICIENT FEED SUPPLEMENTED WITH OXIDISED FAT
}

\author{
K. Stoyanchev*, V. Maruzova \\ Faculty of Veterinary Medicine, Trakia University, Stara Zagora, Bulgaria
}

\begin{abstract}
The purpose of the present study was the experimental reproduction of muscular dystrophy in broiler chickens through early nutrition with a diet deficient in vitamin E, selenium and sulfur-containing amino acids, supplemented with oxidised fat in order to throw light on the etiopathogenesis, clinical signs, diagnosis, course, treatment and prognosis of the disorder. The experiments were conducted with 1 dayold Cobb 500 broiler chickens. By the $3^{\text {rd }}$ day of life, they were divided into 60 experimental and 20 control birds; the latter were fed a standard compound feed whereas the former group received a diet deficient in sulfur-containing amino acids methionine and cysteine (reduced up to 50\%), vitamin E, and Se (from $0.2 \mathrm{mg} / \mathrm{kg}$ in standard feed to $0.01 \mathrm{mg} / \mathrm{kg}$ ), further supplemented with $4 \%$ oxidized fat containing peroxides and aldehydes with peroxide number of the food 8.0 meq $\mathrm{O}_{2} / \mathrm{kg}$. Peroxide number (meq $\mathrm{O}_{2} / \mathrm{kg}$ ) was determined in pork lard oxidised through UV irradiation as per BSS 11374:1986. The clinical signs of experimental muscle dystrophy in broiler chickens appeared first by the $19^{\text {th }}$ day of feeding, when the severe clinical form was established and by the $21^{\text {st }}$ and $25^{\text {th }}$ day in the severe and the mild clinical form. The proportion of diseased chickens during the clinical period was the highest $(93.3 \%$ mild and $46.6 \%$ severe clinical form), and gradually decreased after the treatment with Seled ${ }^{\mathbb{R}}$. The 7-day treatment with Seled ${ }^{\circledR}$ at a dose of $0.06 \mathrm{mg} / \mathrm{kg}$ per os for compensation of Se deficiency and replacement of the deficient compound feed with a regular one contributed to recovery of birds by the $31^{\text {st }}$ day after the therapy of mild experimental muscular dystrophy while birds affected by the severe clinical form could not recovery.
\end{abstract}

Key words: broiler chickens, muscular dystrophy, oxidised fat, deficient feed

\section{INTRODUCTION}

Myopathies in domestic livestock are among important problems of noninfectious pathology. Nutritional muscular dystrophy, also known as "white muscle disease" is one of the commonest myopathies, being first described in mice (1).

Nutritional muscular dystrophy, unlike the congenital muscular dystrophy, results from deficiency of selenium (Se) and vitamin E, as well as from intake of some oxidized dietary fat (2).

Se-deficiency in birds, especially when it is combines with vitamin $\mathrm{E}$ deficiency, is a cause of numerous diseases, including muscular dystrophy, exudative diathesis, nutritional encephalomalacia and nutritional pancreatic atrophy (3).

\footnotetext{
*Correspondence to: Krasimir Stoyanchev, Trakia University, Faculty of Veterinary Medicine - Stara Zagora,Bulgaria, E-mail: ksto@abv.bg
}

McMullin (4) indicated that in birds, muscular dystrophy affects adult, sexually mature subjects, and that the problem is associated with oxidized dietary fat. For prevention of this disease, he recommended supplementation with selenium: $0.15 \mathrm{mg} / \mathrm{kg}$ for young birds under 6 weeks of age and $0.10 \mathrm{mg} / \mathrm{kg}$ for all other ages.

Whitacre and Combs (5) described avian diseases caused by deficiency of $\mathrm{Se}$ and vitamin $\mathrm{E}$ (exudative diathesis, nutritional muscular dystrophy, nutritional pancreatic atrophy). They affirmed that the ration should be cysteine-deficient in order to reproduce muscular dystrophy. Vitamin $\mathrm{E}$ had a protective role against from this condition, but selenium alone was only partly efficient.

Vitamin E - Se deficiency in turkeys differs from the same condition in chickens. In the former bird species, the main sign is the muscular dystrophy of the gizzard, heart and 
pectoral muscles. Unlike chickens, the addition of high doses of selenium did not influence the myopathy. In turkeys, muscular dystrophy is mainly induced by Se deficiency. Vitamin E reduced the amount of Se necessary to prevent the disease $(6,7)$.

In chickens, Cantor et al. (8) reproduced muscular dystrophy through Se-deficient diet with normal vitamin E content. The chickens were hatched from the eggs of breeders, which also received a ration deficient in selenium. After the appearance of specific clinical signs, the authors added $0.4 \mathrm{ppm}$ Se to the diet and established increased live weight and recovery of dystrophic gizzard musculature.

In Bulgaria, Georgiev (9) has studied some diseases including muscular dystrophy in Moscow White and Bronze turkeys breeds, investigating the effect of transportation stress on the clinical course of the disease. He reproduced the disease through feeding birds oxidized fish oil with aldehyde number 198 over 90, 55, 40 days. Turkeys aged 90 days exhibited the specific for muscular dystrophy clinical picture accompanied with retarded growth.

The literature overview shows examples for muscular dystrophy reproduction through feeding Se or vitamin E deficient diet, and in single reports - feeding oxidized diet. No reports were found out where these factors have been used in combinations, as in the clinical practice. Various types of myopathies, including muscular dystrophy are described but they resulted from various types of deficiencies. Clinical signs are described in part together with recommendations for treatment with drugs containing Se or vitamin E. The outcome of the disease, the prognosis and effects of treatment are still unclear.

The aim of the present study was early experimental reproduction of muscular dystrophy through deficiency in vitamin E, selenium, sulfur-containing amino acids and supplemented of the ration with oxidized fat to elucidate the etiopathogenesis, clinical signs, course and treatment in broiler chickens.

\section{MATERIAL AND METHODS}

The experiments were performed in the experimental base of the Department of Noninfections internal diseases, Faculty of Veterinary Medicine, with 80 day-old Cobb 500 broiler chickens.

To eliminate hatchlings' culling and adaptation of newly hatched birds, between the $1^{\text {st }}$ and $3^{\text {rd }}$ day all birds were placed under similar feeding regimen with standard compound feed under optimum housing conditions. On the $3^{\text {rd }}$ day of age, they were divided into control an experimental groups. Control birds received the latter were fed a standard compound feed whereas the experimental group received a diet deficient in sulfur-containing amino acids methionine and cysteine (reduced up to 50\%), vitamin $\mathrm{E}$, and $\mathrm{Se}$ (from $0.2 \mathrm{mg} / \mathrm{kg}$ in standard feed to $0.01 \mathrm{mg} / \mathrm{kg}$ ) but balanced with respect to crude protein energy contents. The compound feed was prepared in the Agricultural Institute - Stara Zagora and supplemented with $4 \%$ oxidized fat containing peroxides and aldehydes with peroxide number of the food 8.0 meq $\mathrm{O}_{2} / \mathrm{kg}$.

Group I - control, 20 broiler chickens fed standard compound feed and housed under optimum hygienic conditions;

Group II - experimental, 60 broiler chickens fed deficient compound feed and housed under optimum hygienic conditions.

Peroxide number (meq $\mathrm{O}_{2} / \mathrm{kg}$ ) as per BSS 11374:1986 was determined in pork lard oxidised through UV irradiation in the Alimenti Laboratory consultative centre for prevention and food safety training, Plovdiv district.

In accordance with the national prevention programme control groups were treated with Seled $^{\circledR}$ at $0.06 \mathrm{mg} / \mathrm{kg}$ per os, between $6-10$ and $16-20$ days of age, while experimental birds did not receive Seled ${ }^{\mathbb{R}}$.

After the $19^{\text {th }}$ day of age, when MD first appeared in the experimental group, the chickens from this group were further divided into 2 subgroups: IIA affected with mild form of the disease and group IIB - affected with severe clinical disease. Both subgroups were housed in separate sections in the same premise.

Clinical signs: general condition, visible mucous coats, body temperature, heart and respiratory rates, appetite, locomotion, adequacy reflexes, sensory perceptions etc. using routine clinical diagnostic approaches. Clinical signs of muscular dystrophy were observed on a daily basis and the course of disease was monitored during its different stages.

On the $21^{\text {st }}$ and $25^{\text {th }}$ day, immediately before the beginning of the treatment, 2 control birds and 2 birds from groups IIA and IIB were submitted to gross and histological examination for detection of MD-specific 
changes in the pectoral, thigh and heart muscles and visceral organs (heart, gizzard, liver). The pathoanatomical study was performed in the Department of General and clinical Pathology, Faculty of Veterinary Medicine, Trakia University Stara Zagora. Histopathological examination was done using classic histological techniques $(10,11)$.

By the $21^{\text {st }}$ and $25^{\text {th }}$ day, 7-day oral treatment with Seled ${ }^{\circledR}$ at $0.06 \mathrm{mg} / \mathrm{kg}$ was initiated in the chickens with mild muscular dystrophy (group IIA) and simultaneously, the deficient feed was replaced with the standard one. In experimental group IIB, the birds were not treated with Seled $^{\circledR}$ and the deficient compound feed was not replaced with normal with regard to full manifestation of clinical signs.
The analysis of numerical data was done with statistical software Statistica $6.0^{\circledR}$ (Stat Soft SEM, USA).

\section{RESULTS}

The monitoring of clinical signs of muscular dystrophy in our experiments revealed the following course of the disease:

There were no birds from the control group affected with muscular dystrophy until the end of the trial.

By the $3^{\text {rd }}$ day of disease course monitoring, the clinical signs were within the physiological norms. By the $19^{\text {th }}$ day of feeding the deficient feed supplemented with oxidized fat, the experimental birds gradually exhibited MDspecific clinical signs - anorexia, ataxia, stiff gait, leg weakness, difficult movement to feeding and watering troughs (Figure 1).

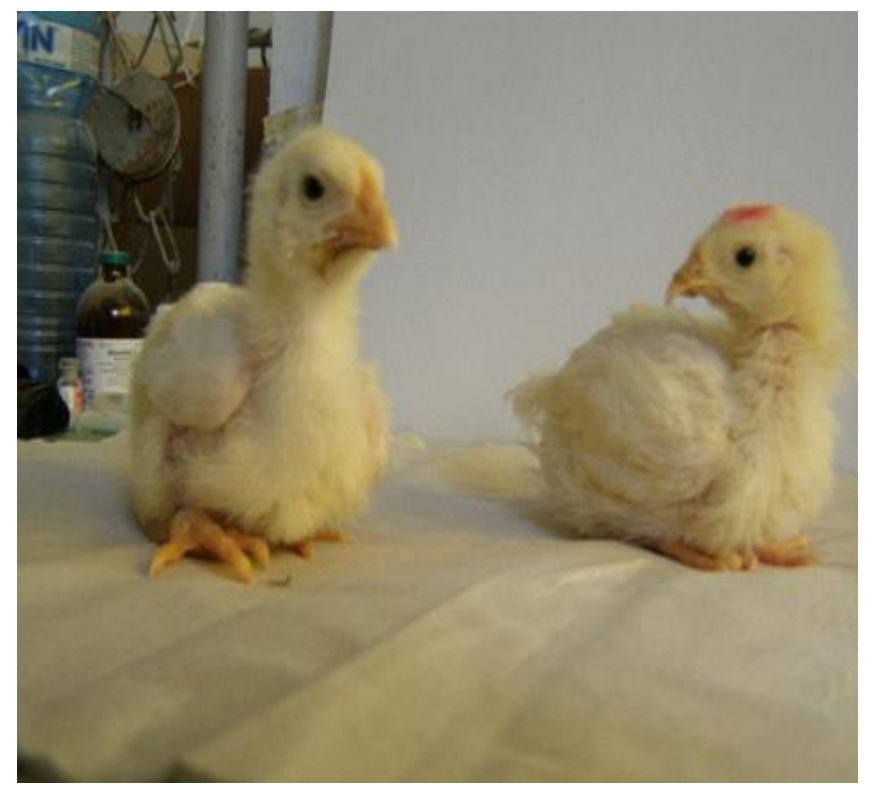

Figure 1. Broiler chickens affected by muscular dystrophy by the $19^{\text {th }}$ day

During more rapid movement, some of chickens fell on the ground, touching it with their chest and abdomen. The wings of some of them were droopy, feathers lost their shining appearance, and became ruffled. The birds from group IIA fell back after being lifted to about half a meter from the ground, but the legs were not able to support the body and they stayed on their chest and abdomen for few seconds, and afterwards got on their feet again and began to walk slowly.

The prevalence of muscular dystrophy among the groups at different days of age are presented in Table 1.

Table 1. Share of the broiler chickens affected by muscular dystrophy before and after treatment with Seled ${ }^{\mathbb{R}}$

\begin{tabular}{|c|c|c|c|c|c|c|c|c|}
\hline \multirow{3}{*}{ Groups } & & \multicolumn{7}{|c|}{ Age (days) } \\
\hline & & \multicolumn{4}{|c|}{ Before treatment } & \multicolumn{3}{|c|}{ After treatment } \\
\hline & $\mathrm{n}$ & 19 & 21 & 25 & $\begin{array}{c}\text { Total } \\
\text { affected }\end{array}$ & 27 & 31 & 39 \\
\hline \multirow[t]{2}{*}{ I. Control } & 20 & - & - & - & & - & - & - \\
\hline & & - & - & - & & - & - & - \\
\hline \multirow{4}{*}{$\begin{array}{l}\text { II. A. Diseased, } \\
\text { mild form }\end{array}$} & \multirow{4}{*}{30} & \multirow{2}{*}{ - } & \multirow{2}{*}{$\begin{array}{c}16 \\
(53.3 \%) \\
\end{array}$} & \multirow{2}{*}{$\begin{array}{c}12 \\
(40 \%)\end{array}$} & \multirow{2}{*}{$\begin{array}{c}28 \\
(93.3 \%)\end{array}$} & \multicolumn{2}{|c|}{ recovered recovered } & \multirow{2}{*}{$\begin{array}{c}\text { total recovered } \\
26(92,9 \%)\end{array}$} \\
\hline & & & & & & $14(50 \%)$ & $12(42,9 \%)$ & \\
\hline & & & & & & diseased & diseased & diseased \\
\hline & & & & & & $2(7,1 \%)$ & - & $2(7,1 \%)$ \\
\hline $\begin{array}{l}\text { II. B. Diseased, } \\
\text { severe form }\end{array}$ & 30 & $\begin{array}{c}7 \\
(23.3 \%)\end{array}$ & $\begin{array}{c}7 \\
(23.3 \%)\end{array}$ & - & $\begin{array}{c}14 \\
(46.6 \%)\end{array}$ & $\begin{array}{c}14 \\
(46.6 \%)\end{array}$ & $\begin{array}{c}14 \\
(46.6 \%)\end{array}$ & $\begin{array}{c}14 \\
(46.6 \%)\end{array}$ \\
\hline
\end{tabular}


The percentage of diseased birds by the $19^{\text {th }}$ day of the clinical course of muscular dystrophy in group IIB (severe form) was $23.3 \%$.

During the next stage of muscular dystrophy development (about the $21^{\text {st }}$ day of feeding), clinical signs in broiler chickens gradually became more pronounced, so that most of experimental birds were hardly capable to stand up, the ataxia became more severe, with paresis and paralysis, stiff gait and lying down in lateral recumbency. The appetite during that period was reduced. The birds were easily exhausted, which was manifested with tachypnea, the beak open, with specific signs of inspiratory dyspnea. The respiratory rate was $43.5 \pm 4.2 \mathrm{~min}^{-1}$ vs $24.3 \pm 2.5$ in controls. The heart rate was $120 \pm 15.5 \mathrm{~min}^{-1}$ vs $178 \pm 5.6$ $\min ^{-1} \quad(\mathrm{p}<0.01)$ in controls. Body temperature of diseased broiler chickens (groups IIA and IIB) was slightly lower - from $40.9 \pm 0.04{ }^{\circ} \mathrm{C}$ to $40.2 \pm 0.09^{\circ} \mathrm{C}$.

The wings of birds were droopy to the ground, with inability to assume their normal position. Other birds stopped to move at all. Palpation of the neck showed firm and hard consistency. The skin was unchanged. The share of affected birds at that time (day 21) was $53.3 \%$ in group IIA and another $23.3 \%$ diseases in group IIB.

In birds from group IIB, leg weakness was progressively transformed into paresis and paralysis. They were recumbent on one side, with stretched legs. Birds moved on their abdomens, one of legs laterally stretched and the other flexed in the tarsal joint. The percentage of affected birds from group IIA at the $25^{\text {th }}$ day of the clinical course of MD increased by another $40 \%$

The total percentage of affected chickens reached $93.3 \%$ in group IIA with mild clinical disease and $46.6 \%$ in group IIB with severe clinical disease.

The administration of Seled ${ }^{\circledR}$ at $0.06 \mathrm{mg} / \mathrm{kg}$ per os was initiated on the $21^{\text {st }}$ day in group IIA until the $27^{\text {th }}$ day and on the $25^{\text {st }}$ day another diseases until the $31^{\text {th }}$ day. In this group, the deficient ration was replaced with standard compound feed.

In experimental group IIB, the birds were not treated with Seled $^{\circledR}$ and the deficient compound feed was not replaced with normal with regard to full manifestation of clinical signs.
During the treatment, the specific signs of MD in experimental birds from group IIA gradually became milder. The gait of birds became more stable, they squatted less frequently and during more intensive movement, some of them fell on the ground but did not seek support with the chest or the abdomen. The wings of some of them were no more droopy, and feathers regained their usual shining appearance and were not ruffled. During the next days, the signs became even more subtle, the major part of birds could stand up, did not exhibit stiff gait during walking, moved without efforts, more rapidly, without staggering and falling. After being lifted to about half a meter from the ground, the chickens fell and stood up after few seconds, moved without efforts and rapidly. The appetite was normalised, as well as the body temperature $-41.1 \pm 0.05{ }^{\circ} \mathrm{C}$. The chickens were no more exhausted, respiratory rate was recovered to $25.5 \pm 3.2 \mathrm{~min}^{-1}$, similar to that in controls $\left(24.8 \pm 3.5 \mathrm{~min}^{-1}\right)$, the heart rate was about $160 \pm 12.5 \mathrm{~min}^{-1}$ vs $176 \pm 4.6$ in controls; the differences between healthy and affected birds were not statistically significant. The wings were no more droopy. During that period, the normal appetite was completely regained. By the $27^{\text {th }}$ day, the share of birds affected with MD in group IIA was only $7,1 \%$. In group IIB, which was not treated with Seled $^{\mathbb{B}}$ and whose deficient ration was not corrected, the percentage of diseased chickens remained the same $-46.6 \%$.

By the $21^{\text {st }}$ and $25^{\text {th }}$ day, alterations in both pectoral and thigh muscles were found out in broiler chickens with MD - they became paler, their colour resembled that of fish meat while no changes were found out in controls. Pathomorphological and histological examinations of chickens by the $19^{\text {th }}$ and $25^{\text {th }}$ day showed muscular dystrophy-specific changes (Figure 2).

\section{DISCUSSION}

The $4 \%$ oxidized fat supplemented to the feed, equivalent to peroxide number $8 \mathrm{meqO}_{2} / \mathrm{kg}$ was fully in line with experiments with chickens performed by Fangfang et al. (12) who used $2 \%$ soybean oil with peroxide number $448.49 \mathrm{meqO}_{2} / \mathrm{kg}$ equivalent to 8.97 $\mathrm{meqO}_{2} / \mathrm{kg}$ peroxide feed number in order to evaluate the effect of oxidative stress on the growth performance and intestinal immunity. 


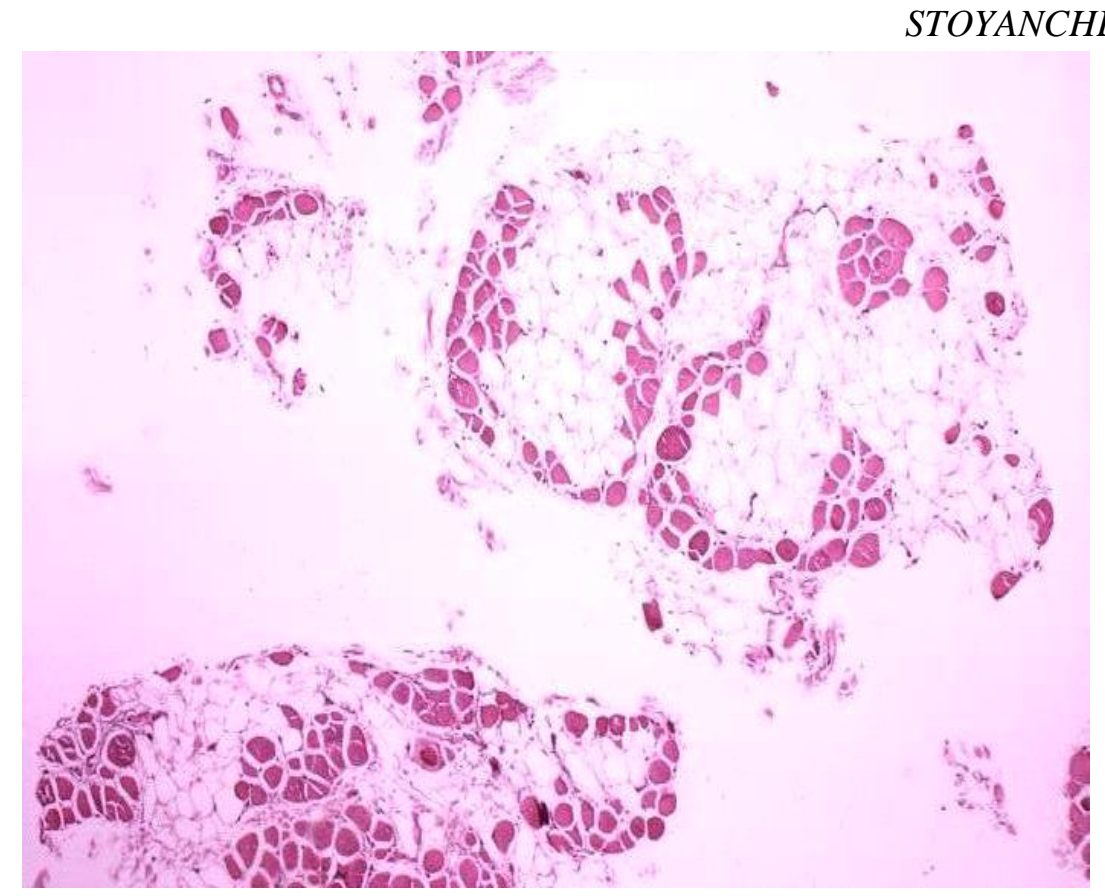

Figure 2. Homogenisation and lysis of some muscle fibres.

Haematoxylin/eosin staining, $260 \mathrm{X}$

On the basis of the present results, we agree with Aliev (13), who described muscular dystrophy as one of the important myopathies in lambs, calves and birds. On the background of literature data the author suggested that apart vitamin E, selenium, sulfur-containing amino acids, ubiquinones, vitamin $\mathrm{A}$, oxidised peroxides, stress was also involved in the pathogenesis of the disease. This made us investigate the combined effect of vitamin $\mathrm{E}$, selenium and sulfur-containing amino acids dietary deficiency together with oxidised peroxides present in oxidised fat. It is believed that vitamin $\mathrm{E}$ and Se participate in oxidation and reduction systems of cell membranes, including mitochondria. They protect lipids and proteins containing either Se or sulfur, or both in their active site, that are specifically sensitive to oxidation $(14,15,16,17)$. Vitamin $\mathrm{E}$ is definitely associated to membrane lipids and its deficiency in rations containing unsaturated fatty acids is manifested with the appearance of lipid peroxides, which are one of caused for the onset of muscular dystrophy (18). This was our rationale for choosing combined vitamin E, Se and sulfur-containing amino acid deficiency and supplementation of oxidised fat in the experimental reproduction of MD.

In Peking ducks, Xu and Diplock (19) have reproduced vitamin $\mathrm{E}$ and Se deficiency and established that MD developed 14 days later with lesions in the gizzard, intestines, heart and skeletal muscles. Due to the fact that we reproduced the muscular dystrophy through dietary deficiency of Se, vitamin $\mathrm{E}$ and $\mathrm{S}$ containing amino acids, we agree with both these authors and statement in Merck Vet. Manual (15), that Se and vitamin E played a pivotal role in several processes one of which is participation in cysteine metabolism and protection of birds from MD. Vitamin $\mathrm{E}$ is localised mainly in the hydrophobic parts of membranes and fat reserve cells. The main function of vitamin $\mathrm{E}$ and $\mathrm{Se}$ is that they are exchangeable in the prevention of deficiency disorders. Our data are in line with those of Combs (20) in hens fed diets with low Se content and peroxidised fat, resulting in myopathies which were then removed by ration supplementation of Se and vitamin $\mathrm{E}$. Olson (21) calso induced MD by vitamin E and sulfur-containing amino acids deficiency in day-old chickens. The deficiency of selenium, especially when combined with low vitamin E, causes the development of various myopathies including exudative diathesis, nutritional encephalomalacia, nutritional pancreatic atrophy and muscular dystrophy (3). It is demonstrated that $\mathrm{Se}$ could delay the manifestation of encephalomalacia, muscular and myocardial myopathies (22).

Jia-Qiang Huang et al. (23) reproduced experimental nutritional MD is four groups of day-old broiler chickens: group 1 - fed ration deficient in Se and vitamin E (- Se - vitamin E), group 2 - deficient in Se but containing vitamin $\mathrm{E}(-\mathrm{Se}+$ vitamin $\mathrm{E})$, group 3 containing Se but deficient in vitamin $\mathrm{E}(+\mathrm{Se}-$ vitamin E) and a control group 4 fed standard feed. A high occurrence of nutritional MD (93\%) was observed by the third week together with $36 \%$ mortality in group 1 , while we 
observed it earlier (day 19) probably due to the combination of applied factors.

McMullin (4) outlined that in birds, the disorder affected older and sexually mature subjects, and that the problem was associated with rancid dietary fat (this type was used in our experiments). Unlike this author, we proved that muscular dystrophy could affect also younger individuals. For prevention of the disease, the author recommended supplementation with $\mathrm{Se}$ at $0.15 \mathrm{mg} / \mathrm{kg}$ for young birds under 6 weeks of age, and at 0.10 $\mathrm{mg} / \mathrm{kg}$ for the others. The levels could be increased if the content of vitamin $\mathrm{E}$ in the diet was low but the content of unsaturated fatty acids - high.

Based on aforementioned reports, Se could delay the appearance of different myopathies. Similarly to McMullin (4), which recommended supplementation with 0.10 $\mathrm{mg} / \mathrm{kg} \mathrm{Se}$, we treated all birds after the complete clinical manifestation of MD. The chosen dose was $0.06 \mathrm{mg} / \mathrm{kg}$ per os, based on some properties of Seled, which make it particularly suitable for MD treatment (18). It is an antioxidant interfering with formation of peroxides of unsaturated fatty acids, playing an important role in the etiology of myopathies. $\mathrm{Se}$ helps the biosynthesis of amino acids (which in our experiment were reduced), it is beneficial for the recovery of structure and function of striated muscles, including the heart, affected by myopathies. It is watersoluble, suitable for application with drinking water, especially in birds affected with different myopathies. It is not toxic even at doses exceeding 40 times the recommended ones. Synonymous preparations are Selevit, Tokosel, Selen -E -sol.

The 7-day treatment with Seled ${ }^{\circledR}$ at $0.06 \mathrm{mg} / \mathrm{kg}$ per os for compensation of Se deficiency resulted in recovery of chickens from group IIA. This outcome could be explained by the data reported by Bartholomew et al. (24), according to which the correction of $\mathrm{Se}$ and vitamin $\mathrm{E}$ deficiency resulting in exudative diathesis, contributed to the rapid recovery of damaged myocytes and replacement with fibrous tissue. After 6 days, many of clinical indices were rapidly restored to values observed in birds fed standard diet. If the feed is rich in selenium and vitamin $\mathrm{E}$, the negative feedback mechanism for membrane stabilisation is triggered $(18,25)$. This could explain the recovery of disease birds in our experiment after oral treatment with 0.06 $\mathrm{mg} / \mathrm{kg} \mathrm{Seled}{ }^{\circledR}$ and replacement of the deficient feed with standard one.

\section{CONCLUSIONS}

In broiler chickens, muscular dystrophy could be reproduced by feeding a compound feed deficient in vitamin $\mathrm{E}$, selenium and sulfurcontaining amino acids (half lower content), supplemented with $4 \%$ oxidised fat to obtain a peroxide number of $8.0 \mathrm{meqO}_{2} / \mathrm{kg}$. The experiment resulted in muscular dystrophy on the $19^{\text {th }}$ day from the beginning of feeding the deficient feed, with severe form in some of birds and subclinical disease in other.

The percentage of diseased broiler chickens affected with mild MD was $93.3 \%$, while those affected with severe muscular dystrophy $46.6 \%$.

The 7-day treatment with Seled ${ }^{\circledR}$ at $0.06 \mathrm{mg} / \mathrm{kg}$ per os for compensation of Se deficiency and replacement of the deficient compound feed with a regular one contributed to recovery and normalisation of body temperature, heart and respiratory rates of birds with mild experimental muscular dystrophy.

The birds affected by the severe clinical form of disease, which were not treated with Seled ${ }^{\circledR}$ and whose deficient feed was not corrected, could not recover and the proportion of affected birds (46.6\%) did not change until the end of the experiment.

\section{REFERENCES}

1. Payne,E.T.,N.Yasuda,J.M.Bourgeois,M.C. Devries,M.C.Rodrigues,J.Yousuf, Muscle Nerve, 33(1),66-77, 2006.

2. Todorovic, M.; Jokic, Z.; Davidovic, V, The influence of selenium and vitamin $E$ in poultry nutrition / Znacaj selena i vitamina $\mathrm{E}$ u ishrani zivine, Biotechnology in Animal Husbandry, 18 (5/6), p.231-238, 2002.

3. Surai, P. F. and J.E. Dvorska., Effect of Selenium and vitamin E content on lipid peroxidation in breast muscle tissue of broiler breeder hens during storage. Proc. Aust. Poult. Sci. Symposium. 14: 187-192, 2002.

4. McMullin, P., 2004. Vitamin E deficiency, encephalomalacia, exudative diathesis, muscular Dystrophy, Poultry health and disease.

5. Whitacre, M.E. and G.F. Combs, Jr. Peroxidative damage in nutritional pancreatic atrophy due to selenium deficiency in the chick. Federation Proc., 42:928, 1983.

6. Walter, E.D., L.S. Jensen, Effectiveness of Selenium and noneffectiveness of Sulfur amino acids in preventing muscular dystrophy in the turkey poult, J. Nutrition, 80: '63, 327-331, 1980. 
7. Chang, W. P.; Combs, G. F., Jr.; Scanes, C. G.; Marsh, J. A., The effects of dietary vitamin $\mathrm{E}$ and selenium deficiencies on plasma thyroid and thymic hormone concentrations in the chicken. Developmental and Comparative Immunology. 29 (3),.265-273, 2005.

8. Cantor AH, Moorhead PD, Musser MA., Comparative effects of sodium selenite and selenomethionine upon nutritional muscular dystrophy, selenium-dependent glutathione peroxidase, and tissue selenium concentrations of turkey poults. Poult. Sci., 2, 61(3):478-84, 1982.

9. Georgiev, H., 1979. Investigations on some diseases in turkeys associated with selenium and vitamin E deficiency. Higher Institute of Zootechnics and Veterinary Medicine, Stara Zagora, 78 - 102.

10.Dzhurov, A., E. Alexandrova, M. Alexandrov, 1989, Techniques for histopathological examination. Zemizdat, Sofia, 28-34, 1989.

11.Dyakov, L., L. Lozanov, A. Angelov and D. Stoykov. Manual of veterinary histopathology, Zemizdat, Sofia,1989.

12.Fangfan, L., Shongun, J., Yi, M., Guilian, Z., Lin, Y., Consumption of Oxidizet Soybean Oil Increased Intestinal Oxidative Stress and Affected Intestinal Immune Variables in Yellow - feathered Broilers, Asian Australas. J. Anim. Sci., 2015.http/dx.doi.org/10. 5713/ajas. 14. 0924.

13. Aliev A., V. Barei, P. Bartko, Y. Bouda, R. Dzhordzhak, P. Gabrashanski, L. Vrzgula, 1985, Diseases secondary to impaired metabolism in domestic animals, Zemizdat, Sofia, 240 - 251.

14.Mahmoud, K. Z., and F. W. Edens.. Influence of selenium sources on agerelated and mild heat stress-related changes of blood and liver glutathione redox cycle in broiler chickens (Gallus domesticus). Comp. Biochem. Physiol., B 136: 921-934, 2003.

15.Merk Veterinari Manual, 2006, Nutritional Requirements. Vitamin E deficiency, USA

16. Kuttappan VA, Goodgame SD, Bradley $\mathrm{CD}$, Mauromoustakos A, Hargis BM, Waldroup PW, Owens CM., Effect of
STOYANCHEV K., et al.

different levels of dietary vitamin E (DL- $\alpha-$ tocopherol acetate) on the occurrence of various degrees of white striping on broiler breast fillets., Poult. Sci., 91(12):3230-5, 2012.

17.Huang JQ, Ren FZ, Jiang YY, Xiao C, Lei XG., Selenoproteins protect against avian nutritional muscular dystrophy by metabolizing peroxides and regulating redox/apoptotic signaling., Free Radic Biol. Med., 83:129-38, 2015.

18. Gabrashanski, P., Kovalski, M. Rish, L. Nedkova, D. Aboulaev, 1979, Trace elements and trace element deficiencies in industrial livestock husbandry, ZemizdatSofia-Moscow

19.Xu GL, Diplock AT., Glutathione peroxidase (EC 1.11.1.9), glutathione-Stransferase (EC 2.5.1.13), superoxide dismutase (EC 1.15.1.1) and catalase (EC 1.11.1.6) activities in tissues of ducklings deprived of vitamin $\mathrm{E}$ and selenium,: $\mathrm{Br} J$ Nutr. ,50(2):437-44, 1983.

20.Combs, G. F., Jr., and M. L. Scott, 1974. Dietary requirements for vitamin $\mathrm{E}$ and selenium measured at the cellular level in the chick. J Nutr 104: 1292-1296.

21.Olson R.E., Creatine kinase and myofibrillar proteins in hereditary muscular dystrophy and vitamin E deficiency,Am.J.Klin.Nutr.,27,1117-1129, 1974.

22.Diplock, A.T., Metabolic aspects of selenium action and toxicity. CRC Crit. Rev. in Tox., 4: 271-329, 1976.

23.Jia-Qiang Huang, Fa-Zheng Ren, Yun-Yun Jiang, Chen Xiao, Xin Gen Lei, Selenoproteins protect against avian nutritional muscular dystrophy by metabolizing peroxides and regulating redox/apoptotic signaling, Free Radical Biology and Medicine, 83, 129-31, 2015.

24. Bartholomew A, Latshaw D, Swayne DE, Changes in blood chemistry, hematology, and histology caused by a selenium/vitamin E deficiency and recovery in chicks, Biol Trace Elem Res. ,62(1-2):7-16, 1998.

25.Hidiroglou, M., I. Hoffman, K.Jenkins, In: Trace Element Metabolizm in Animals, Edinburgh - London, 1970, p. 272. 